\title{
Optimising stope design and ground support - a case study
}

\author{
R.M. Stephenson AMC Consultants Pty Ltd, Australia
}

M.P. Sandy AMC Consultants Pty Ltd, Australia

\begin{abstract}
Initial stope spans and ground reinforcement designs at a gold mine in Western Australia were based on rock mass classification and empirical methods. As stoping experience was gained, these designs were found to be conservative and gradually the spans were increased. Back-analysis of stoping performance provided an insight into the factors controlling failure and dilution. Reinforcement designs were modified with ongoing stoping experience to minimise dilution. Stope designs were subsequently optimised, allowing larger stopes to remain stable using the modified reinforcement designs.
\end{abstract}

\section{$1 \quad$ Introduction}

Long-hole open-stoping methods have been implemented in several orebodies at a gold mine in Western Australia. The orebody under study exists within a series of closely spaced shears within andesite, volcaniclastics, and felsic porphyry host rocks. The mineralised zones are hosted in sulphide-rich breccia veins that dip 60 to $80^{\circ}$ towards west. The lodes are transected by shallow west-dipping faults and steep north-south striking faults. The overall zone of economic ore dips at $70^{\circ}$ to the east.

Bulk mining has been successfully implemented at the project, using sublevel long-hole open-stoping primary/secondary methods. The sublevel spacing is $25 \mathrm{~m}$ vertical floor to floor. The majority of stopes are $30 \mathrm{~m}$ along strike, $25 \mathrm{~m}$ wide, $80 \mathrm{~m}$ high and contain around 170,000 tonnes. Following the completion of extraction, each stope is surveyed using the cavity monitoring system (CMS) prior to being pastefilled.

The mining area is approximately $200 \mathrm{~m}$ long, $30 \mathrm{~m}$ wide, and extends from 480 to $680 \mathrm{~m}$ below surface. A $50 \mathrm{~m}$ thick crown pillar exists between the top of the main stoping area and the pit floor. Another stope was extracted adjacent to the crown pillar between $430 \mathrm{~m}$ and $480 \mathrm{~m}$ below surface. Figure 1 shows the sequence and layout of the stopes. 


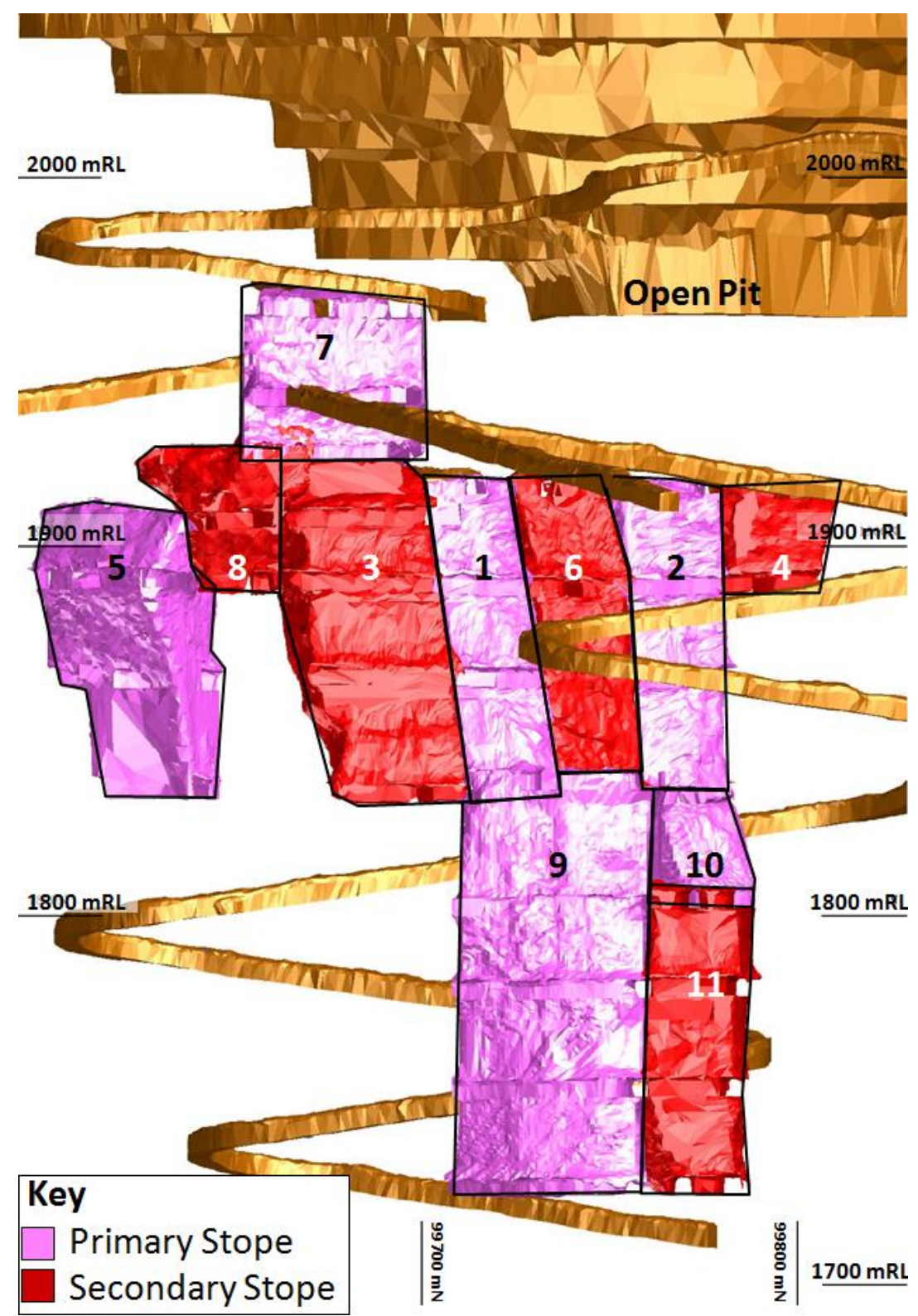

Figure 1 Longitudinal section of the mining area showing the sequence and layout of stopes

\subsection{Geotechnical processes}

The geotechnical department at the mine works closely with the planning engineers and underground manager to ensure successful extraction of the large stopes. Stope designs are carefully reviewed by the geotechnical engineers and discussed in detail with the planning engineers to achieve optimum geotechnical designs. A sign-off process follows, which documents the conclusions of those discussions, for approval by management. A team-based risk assessment is conducted for each stope as part of the standard risk mitigation process.

When geotechnical issues are encountered during the mining process they are investigated, reported, and communicated to technical services and operations. Lessons are learnt as stoping progresses and the mine designs constantly evolve around a set of 'rules'.

The geotechnical department has the support of an annual geotechnical review panel to ensure the most appropriate practices are adopted at the mine. The review panel is an integral part of the evolution of mining practices and design procedures at the project with the aim of achieving the maximum extraction within the capabilities of the rock mass. 
Procedures have an important role in mitigating risk and standardising work processes within the geotechnical department. Procedures are in place to cover all aspects of monitoring, data collection, and analysis.

\section{Initial geotechnical analysis}

\section{$2.1 \quad$ Rock mass classification}

Extensive mapping of development at the project provides information for determining the rock mass properties. The rock mass is generally of a high quality throughout the orebody, although in some localised areas persistent structures cause blocky ground conditions. The $Q$ system (Barton et al., 1974) is used to characterise the rock mass. Table 1 summarises the values used as inputs to the $Q$ calculations and the results.

Table 1 Values used in $\mathrm{O}$ calculations

\begin{tabular}{ccc}
\hline Input & Range & Typical \\
\hline RQD & $80-90$ & 90 \\
Joint number Jn & $4-9$ & 6 \\
Joint roughness Jr & $1-3$ & 2 \\
Joint alteration Ja & $1-2$ & 1 \\
Joint water condition & 1 & 1 \\
Jw & $1-2.5$ & 1 \\
Stress reduction factor & \\
(SRF) & $11-67$ & 30 \\
Q &
\end{tabular}

The rock quality designation (RQD) Deere (1968) has been estimated from line mapping because no geotechnical core logging data was available. The estimation has a good correlation with core photographs.

The SRF was calculated from uniaxial compressive strength (UCS) values and in situ stress measurements using both hollow inclusion and Western Australian School of Mines acoustic emission methods. The UCS tests range from 156 to $230 \mathrm{MPa}$ for failure through intact rock. The principal stress magnitudes $\left(\sigma_{1}, \sigma_{2}\right.$, and $\left.\sigma_{3}\right)$ and average ratio of horizontal to vertical stress $(k)$ applied at the mine is shown in the equations:

$$
\begin{gathered}
\sigma_{1}=0.0663 \times \operatorname{depth}(\mathrm{m})+10 \text { at } 06^{\circ} / 155^{\circ} \\
\sigma_{2}=0.0221 \times \operatorname{depth}(\mathrm{m})+14 \text { at } 20^{\circ} / 063^{\circ} \\
\sigma_{3}=0.0299 \times \operatorname{depth}(\mathrm{m}) \text { at } 69^{\circ} / 260^{\circ} \\
k=2.8
\end{gathered}
$$

Underground observations indicate a low stress environment at current depths with no signs of stressinduced damage.

\subsection{Kinematic analysis}

An important characteristic of the rock mass that is not considered in rock mass classification, using the $Q$ method, is the persistence of structures. The majority of structures in the orebody are discrete but there are enough continuous structures present at drive-scale and stope-scale length that they are considered to be ubiquitous in the rock mass (Figure 2). 


\section{Persistence}

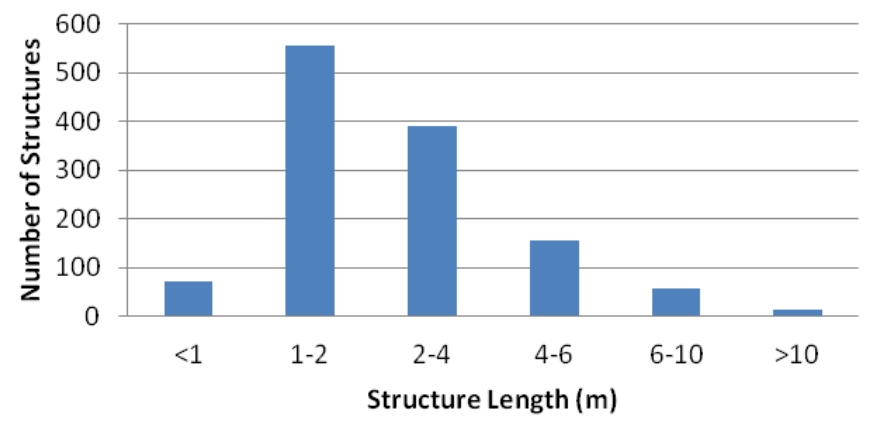

Figure 2 Persistence of mapped structures in the rock mass

Kinematic analyses are completed for each stope extracted. The mapping data used for each analysis is collected from development proximal to the stope (typically 100 poles). Each wall is assessed for toppling and wedge failure using the Rocscience program Dips (Hoek and Diderichs, 1989). The potential for wedge failures to occur are assessed for the backs of all stopes. Most of the analyses for stope hangingwalls indicate the potential for wedge failure. The sidewalls and footwall of the stopes are generally predicted to be stable. An example of the kinematic analysis is shown in Figure 3.
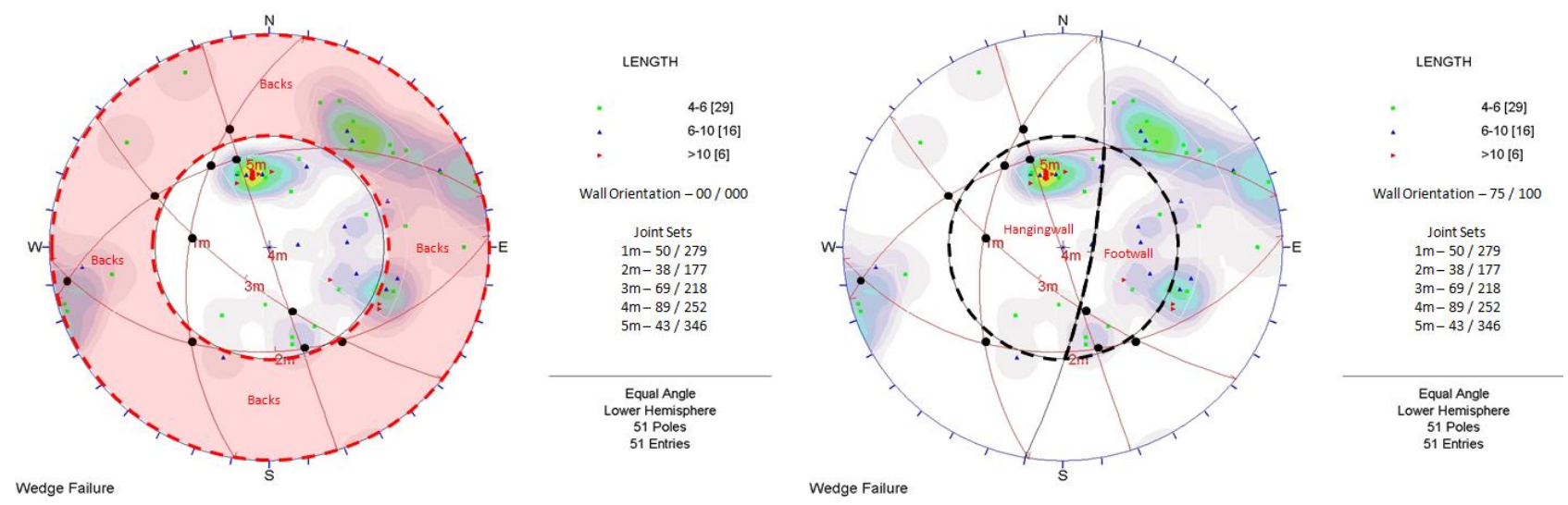

Figure 3 Example of kinematic analysis showing potential wedge failures

Large scale structures are included in the initial geotechnical analyses. One fault transects the orebody, intersecting the hangingwall of the No. 9 stope and the backs of the No. 11 stope. Where encountered, other persistent joints are mapped to assess the risk of stope wall or brow failures.

\subsection{Stope stability analysis}

The stability graph method, originally proposed by Mathews et al. (1980) and subsequently by Potvin (1988), is an empirical method for the design of open stopes and ground reinforcement. It has since been modified by Nickson (1992). These modifications have been applied in the back-analysis assessments presented here.

The initial stope wall stability assessments at the project had applied conservative values for the 'A Factor', as is typical in the early stages when no local mining experience is available. The A factor varies with the depth (below surface) of the stope wall and whether the stope was primary or secondary.

The A factor values have since been adjusted to better reflect actual mining experience.

Each stope wall has been assessed for the modified stability number $\mathrm{N}^{\prime}$, the results for which are shown in Table 2. 
Table 2 Values used in $\mathrm{N}^{\prime}$ calculations

\begin{tabular}{|c|c|c|c|c|}
\hline Stope Wall & Input & Minimum & Maximum & Typical \\
\hline \multirow[t]{5}{*}{ Hangingwall } & $Q^{\prime}$ & 11 & 67 & 30 \\
\hline & $A$ & 0.52 & 1 & 0.85 \\
\hline & B & 0.2 & 0.95 & 0.65 \\
\hline & C & 3.8 & 8 & 6.4 \\
\hline & $\mathbf{N}^{\prime}$ & 37 & 338 & 100 \\
\hline \multirow[t]{5}{*}{ Footwall } & $Q^{\prime}$ & 11 & 67 & 30 \\
\hline & $A$ & 0.52 & 1 & 0.85 \\
\hline & B & 0.44 & 0.89 & 0.77 \\
\hline & C & 4.5 & 8 & 8 \\
\hline & $\mathrm{N}^{\prime}$ & 17 & 410 & 152 \\
\hline \multirow[t]{5}{*}{ Side wall } & $Q^{\prime}$ & 11 & 67 & 30 \\
\hline & $A$ & 0.52 & 1 & 0.85 \\
\hline & B & 0.92 & 0.98 & 0.98 \\
\hline & C & 8 & 8 & 8 \\
\hline & $\mathbf{N}^{\prime}$ & 61 & 473 & 193 \\
\hline \multirow[t]{5}{*}{ Backs } & $Q^{\prime}$ & 11 & 67 & 30 \\
\hline & $A$ & 0.7 & 1 & 1 \\
\hline & B & 0.43 & 0.58 & 0.43 \\
\hline & C & 2 & 2 & 2 \\
\hline & $\mathbf{N}^{\prime}$ & 9 & 75 & 27 \\
\hline
\end{tabular}

The results of the $\mathrm{N}^{\prime}$ calculations for each stope wall in the orebody are shown in Figures 4 and 5 . Figure 4 shows the total hydraulic radius (HR) without reinforcement and Figure 5 shows the unsupported hydraulic radius between the reinforced 'beams' of cable bolting on each sublevel (Calvert et al., 2000). When plotted on the stability chart which applies the curve based on Nickson, 1992 (Hutchinson and Diederichs, 1996), most of the stope walls plot in the stable section of the graph. Despite the results of the $N^{\prime}$ calculations for the back-analysis study, the stope hangingwalls were supported with cable bolts. The initial conservative values used for ground support designs in the orebody plotted in the unstable region of the graph. 


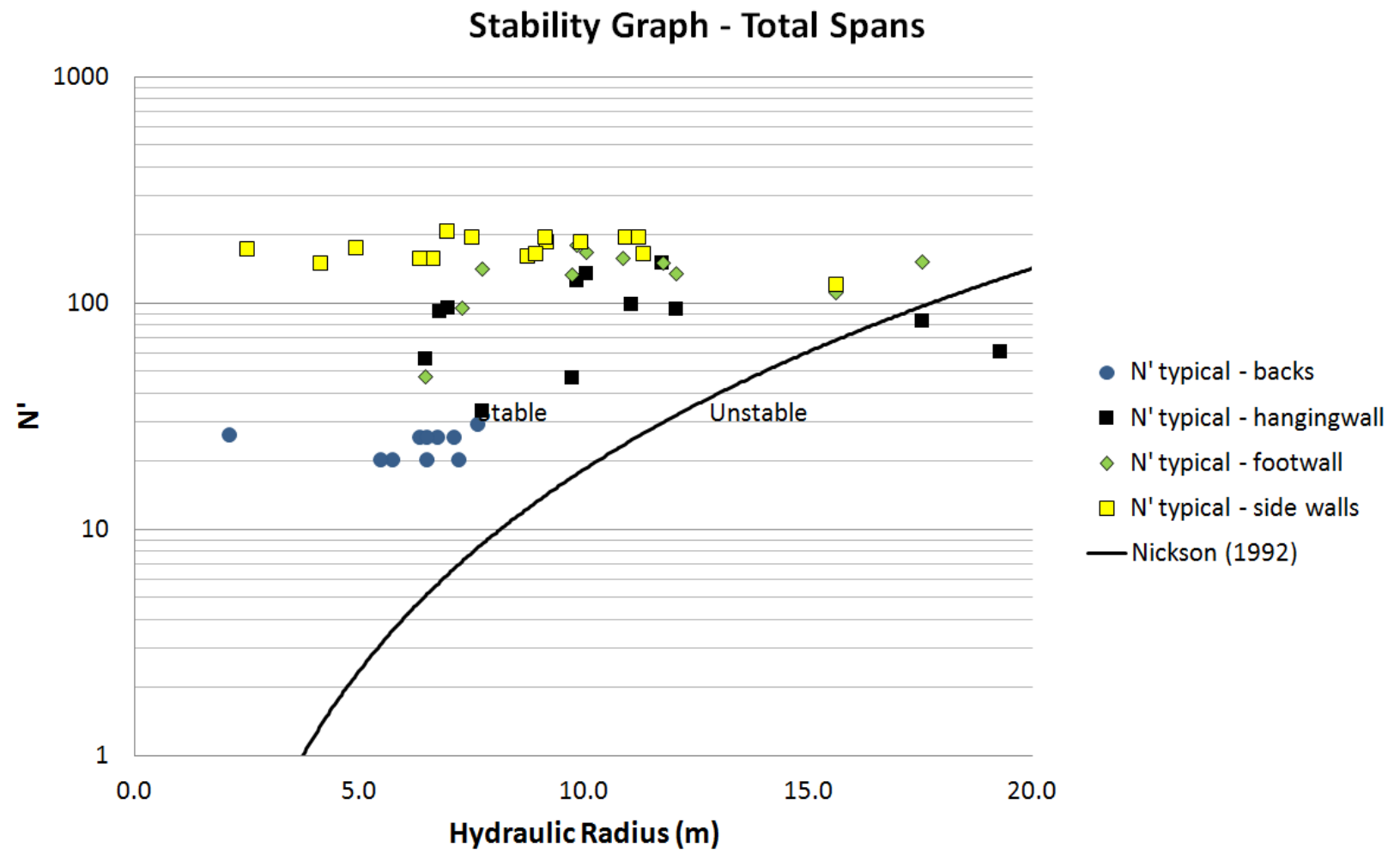

Figure 4 Stability graph with total spans

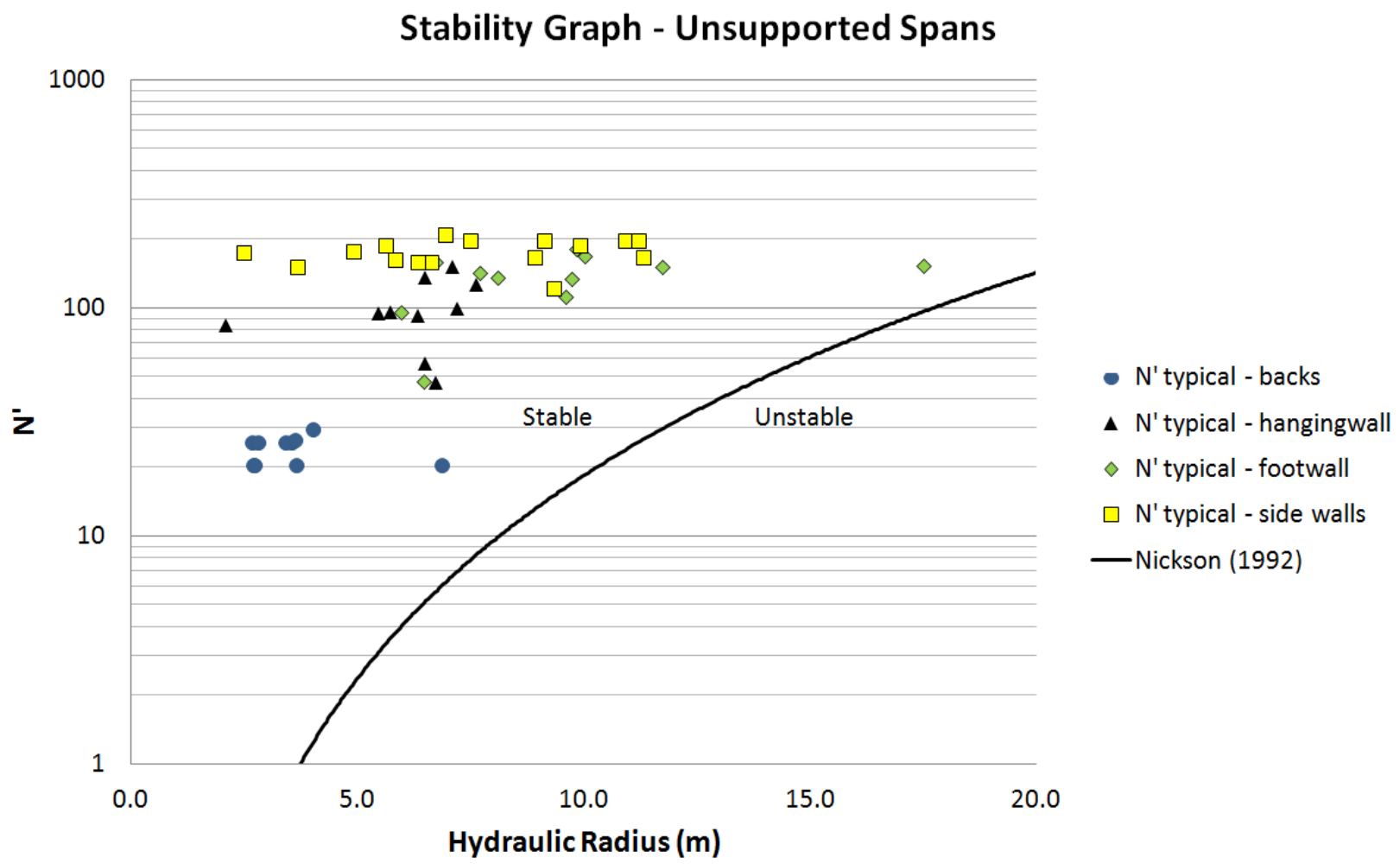

Figure 5 Stability graph with unsupported spans

\subsection{Numerical model}

The boundary element linear elastic program Map3D is used at the project to analyse the influence of mining-induced stress. An iterative process was followed to progress from single stope designs and influences on proximal development to determining stope sequences for the orebody. Figure 6 shows a 
comparison of different sequences. These results were used to select the option that will experience the least change in stress (Sequence 3). Only minor instances of mining-induced stress-driven failure in the rock mass have been observed at the project. Because of this the model is not 'calibrated' and the modelled values have not been used in $\mathrm{N}^{\prime}$ calculations.

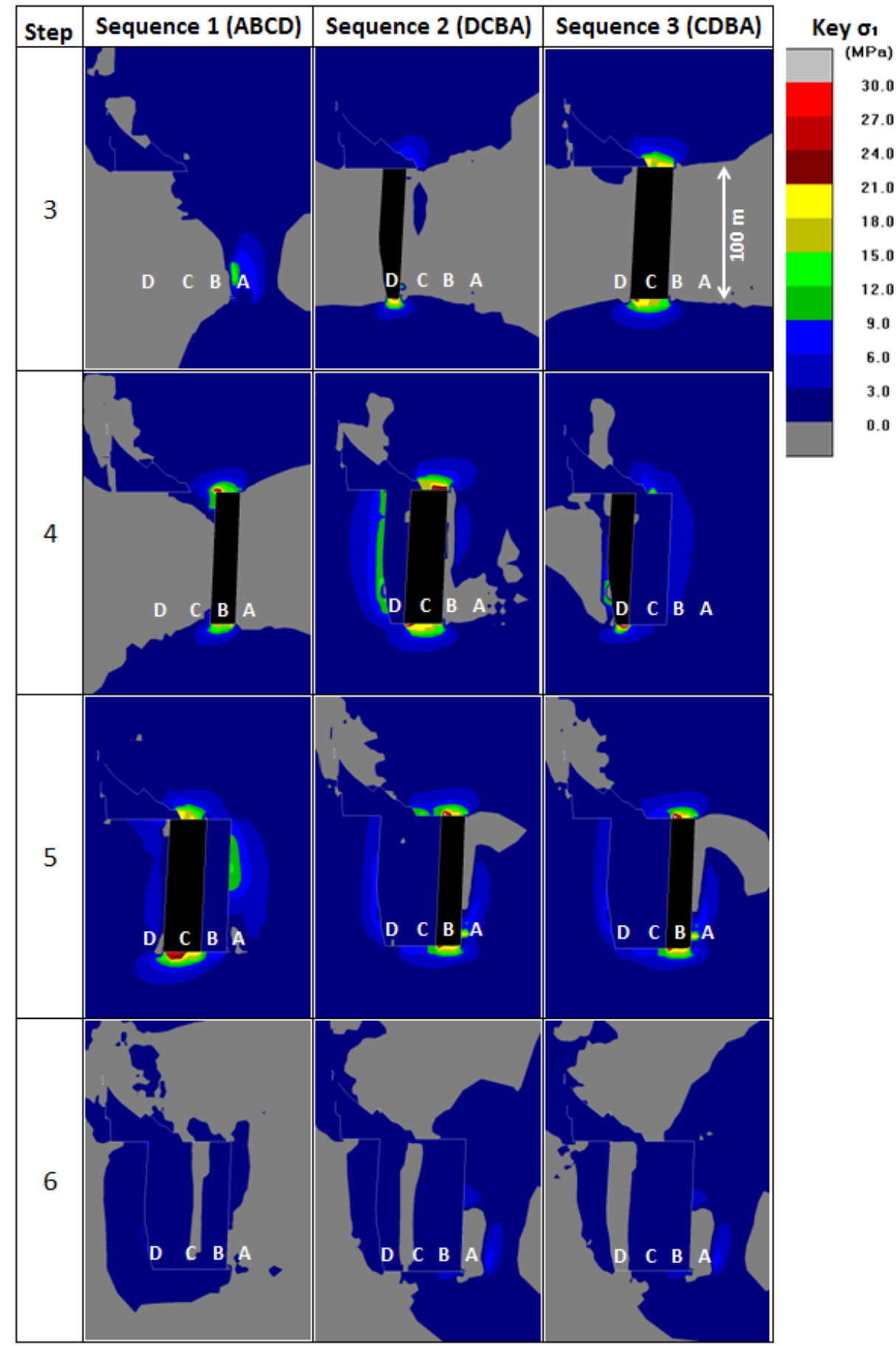

Figure 6 Major principal stress change contours to compare sequence options plotted on a longitudinal section looking west

\subsection{Ground support designs}

Development in the orebody is supported with $50 \mathrm{~mm}$ thick fibrecrete and $2.4 \mathrm{~m}$ long Posimix bolts. Intersections are usually reinforced with $6 \mathrm{~m}$ long twin-strand bulbed cable bolts installed in two phases before and after the 'drag' cuts. Intersections located in and around the upper panel of stopes were 
reinforced with twelve $9 \mathrm{~m}$ cable bolts in the centre and six $6 \mathrm{~m}$ cable bolts in the 'fillets' resulting from the drag cuts.

The hangingwall and backs of the stopes were reinforced with $10 \mathrm{~m}$ long twin-strand bulbed cable bolts. A standard cable bolt design for these stopes is shown in Figure 7. These designs were based on the initial more conservative values that were plotted on a stability graph and numerical modelling analyses.

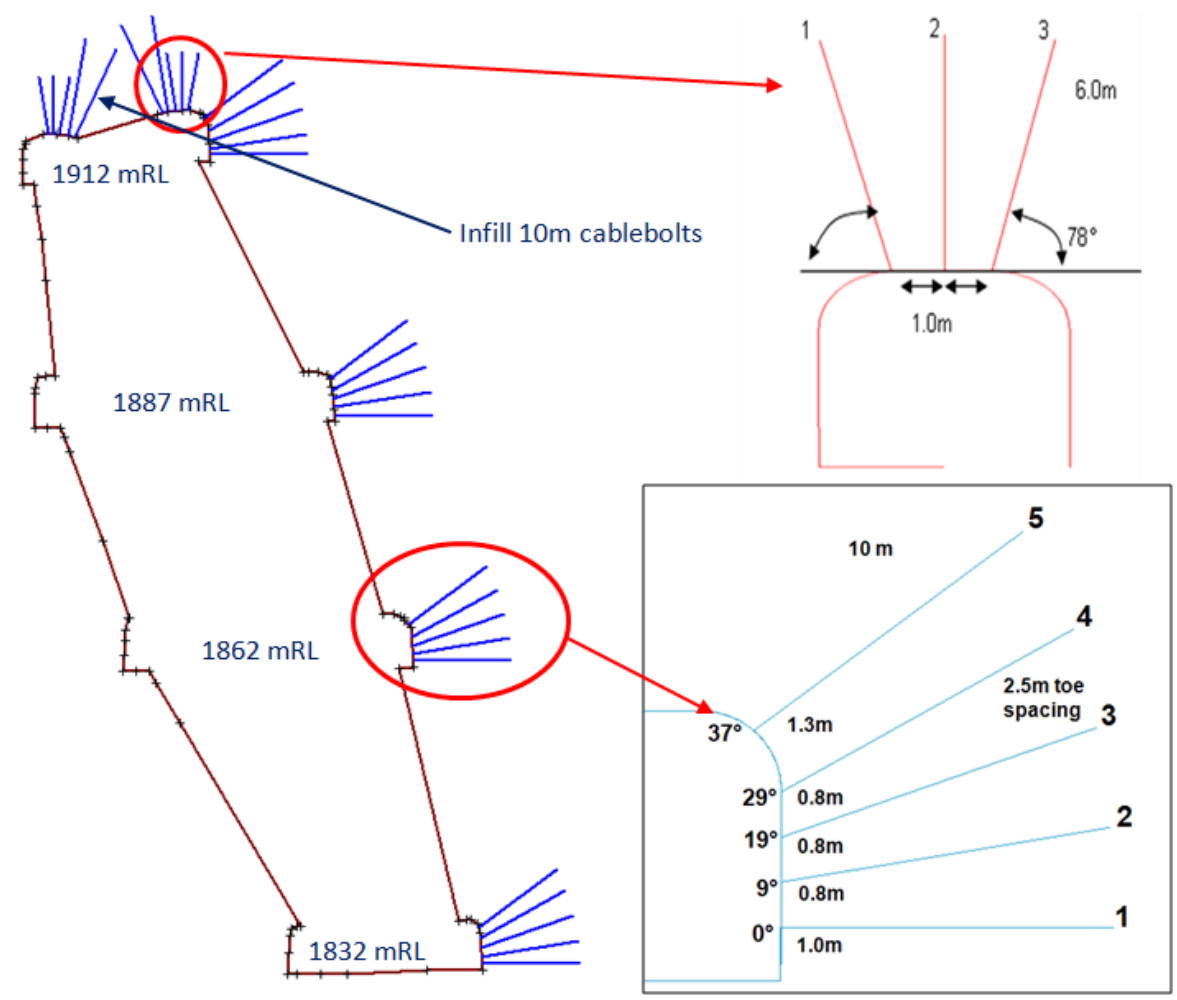

Figure 7 Standard reinforcement designs for stopes

\section{$3 \quad$ Monitoring stope performance}

\subsection{Rock mass monitoring}

Arrays of multi-point rod extensometers were installed into the footwall, hangingwall, sidewalls, and backs of most of the stopes. The data was collected using an electronic readout unit prior to firing, after firing, and once to twice per week. The extensometers recorded very small ground movements $(0-4 \mathrm{~mm})$ in most cases. Larger movements were recorded in the No. 2 stope hangingwall, No. 6 stope backs, No. 1 stope sidewall, and No. 7 stope backs. These could generally be correlated with stope firings.

A seismic system is installed at the mine. The system is comprised of a combination of uniaxial and triaxial geophones surrounding the upper levels of the orebody. No significant seismic events have been recorded by the seismic system and rock noise was seldom reported by the underground workforce, consistent with the low to moderate stress environment.

CMS surveys are conducted for all stopes. As a minimum, a survey is conducted the conclusion of each stope and compared with the design shape to reconcile for geological and geotechnical purposes. Occasionally, 'interim' surveys are conducted following a stope firing to investigate problems with blasting or stope wall failures.

\subsection{Observations}

Routine geotechnical inspections are conducted in each active stoping and development area at least once per week. Inspections are also conducted following mass blasts in the stopes. Damage to the rock mass 
close to blasted stopes is sometimes observed particularly in areas where the pillars are relatively thin. These areas are usually rehabilitated with $50 \mathrm{~mm}$ thick fibrecrete and $2.4 \mathrm{~m}$ long Split Sets. The primary support has been largely successful in minimising the need for rehabilitation.

The brows of active stopes are inspected on a regular basis. Structurally controlled failures have occurred on two occasions at stope brows causing delays in production and rehabilitation.

Stope backs have also experienced instability. Pastefilling of the large stopes can take several months and failures in the backs have been observed prior to the stopes being tight-filled. These are often associated with blasting in nearby stope blasts.

On initial extraction, the No. 1 stope backs were stable and the stope was not tight-filled. Extraction of the adjacent No. 3 stope resulted in the formation of a large open span across both stope backs. There was limited opportunity for reinforcement to be installed in these stopes. A large failure (about 16,000 t) occurred in several stages up to three months after the last production rings were fired. A wedge had formed bounded by large-scale structures. The failed material was high grade ore that could not be recovered. One section of high grade ore in the No. 8 stope was sterilised as a result of the failure.

The No. 4 stope is a secondary stope situated in the northern abutment of the orebody. The stope was not tight-filled and had been left open for four months when a back failure occurred. The $800 \mathrm{t}$ of failed material appeared blocky in nature and shallow-dipping structure surfaces were observed in the backs.

The No. 6 stope is a secondary stope and was the final pillar remaining in the main central panel. A failure of about $900 \mathrm{t}$ occurred from the backs when a mass blast was fired in the No. 7 stope, two months after the final production rings were fired in the No. 6 stope. Pastefilling had not yet commenced in this stope.

A back failure occurred in the No. 7 stope, a primary stope extracted close to the pit floor. A failure of about 1,800 t occurred during pastefilling of the stope, eight months after the last production rings were fired. A wedge had formed which was defined by steep-dipping and shallow-dipping structures.

The mechanism of each failure that has occurred to date in the orebody is gravitational wedge failure. A number of failures were assisted by nearby stope blasting but all were time-dependent.

\section{$4 \quad$ Stope back-analysis}

\subsection{Back-analysis process}

At the completion of each stope a CMS survey is provided by the survey department. The CMS is compared with the design shape using a 3D mine design program (such as Surpac). A shape is constructed that provides a volume of the overbreak for each stope wall. An example of this process is shown in Figure 8. 

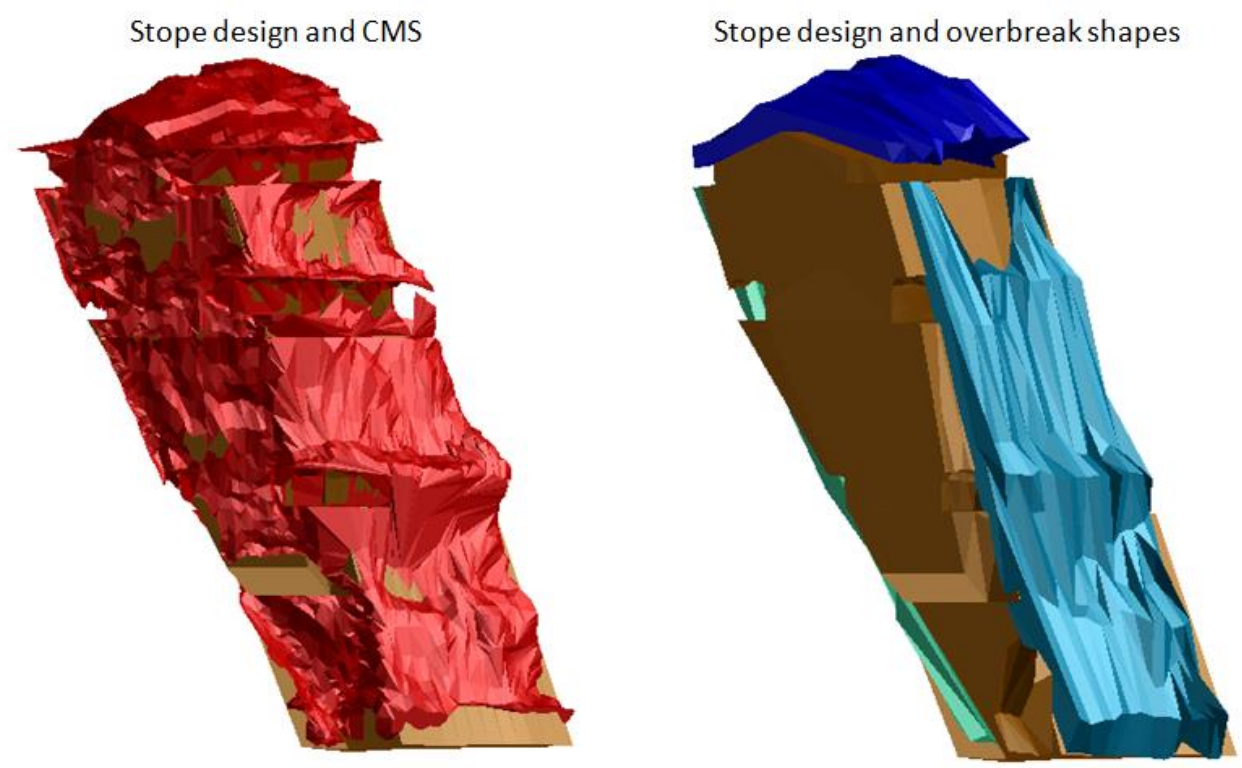

Figure 8 Comparison of stope design shapes with CMS and constructed overbreak shapes

The amount of overbreak can be quantified using the Equivalent Linear Overbreak/Slough (ELOS) method described by Pakalnis et al. (1996), defined by the equation:

$$
\text { ELOS }=\frac{\text { measured volume of overbreak }\left(\mathrm{m}^{3}\right)}{\text { width }(\mathrm{m}) \times \text { height }(\mathrm{m})}
$$

ELOS gives the average depth of overbreak relative to the span where the overbreak originated. Spans can be compared directly with one another using this method. ELOS values for all stope walls are plotted on a stability graph together with an indication of whether failure occurred. The ELOS values were categorised following collation of all the data for extracted stopes, as shown in Table 3. The category descriptions have been changed from that suggested by Pakalnis et al. (1996) to match stope performance in the orebody.

\section{Table 3 ELOS categories}

\begin{tabular}{cc}
\hline ELOS Value $(\mathrm{m})$ & Category Description \\
\hline $0-1$ & Stable \\
$1-3$ & Overbreak \\
$>3$ & Significant overbreak \\
\hline
\end{tabular}

\subsection{Results}

The results of the ELOS calculations are plotted on the stability graph (Figure 9). The HR used in the backanalysis corresponds to the 'unsupported span' meaning the span between 'beams' of cable bolting on each sublevel. The unsupported spans in the orebody (expressed as hydraulic radii) were typically $3.2 \mathrm{~m}$ in the backs and $6.7 \mathrm{~m}$ in the hangingwall. The $\mathrm{N}$ ' values correspond to the 'typical' values. 


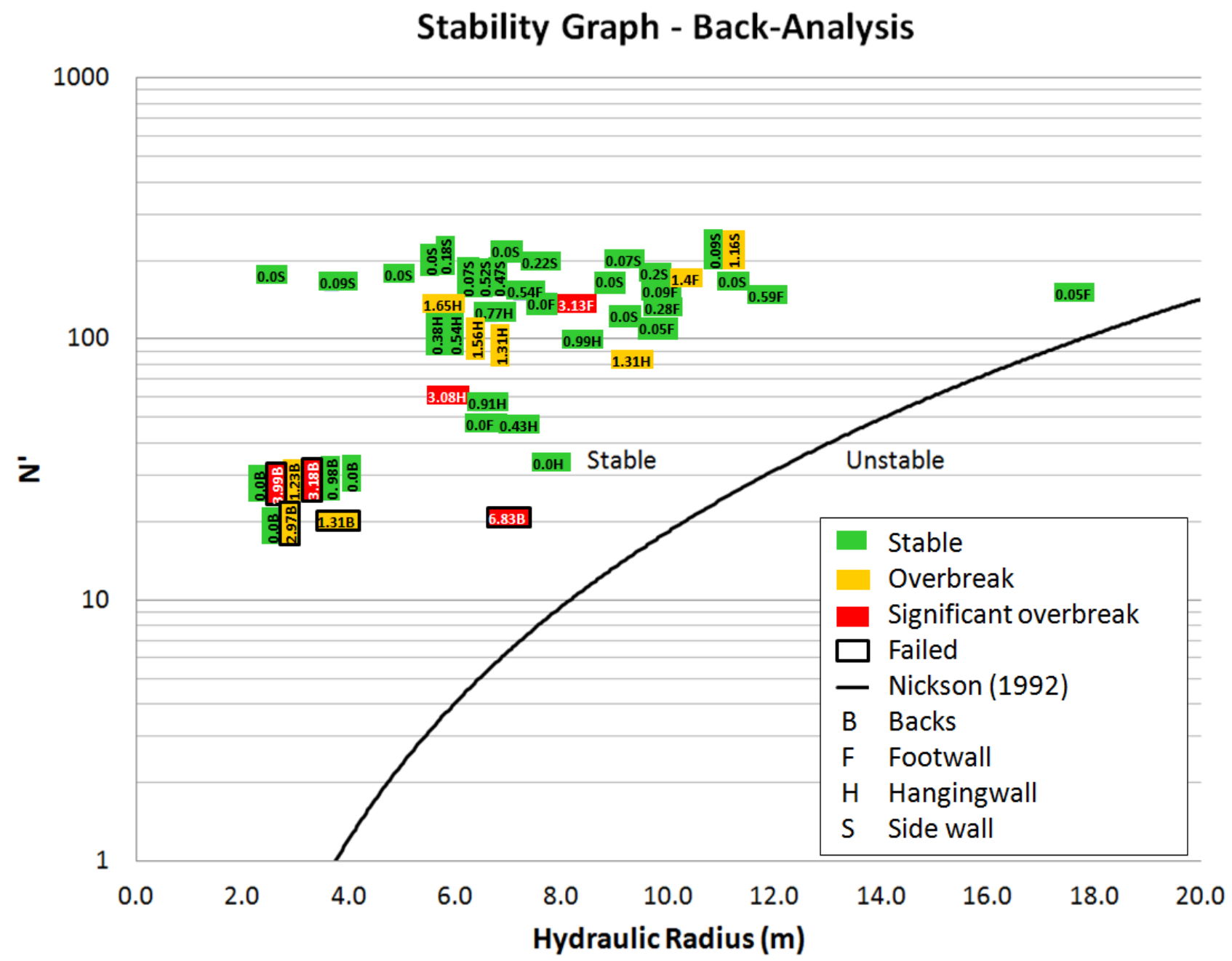

Figure 9 Stability graph presenting back-analysis data

The back-analysis data does not fit with the Nickson (1992) curve. Difficulties arise when attempting to fit a new curve to the data as there is no clear grouping of the data; 'stable' points plot adjacent to 'significant overbreak' points. No obvious structural controls were observed for the data points representing 'significant overbreak', but where no failure had occurred. Other controlling factors may require consideration, such as blasting and notching of the stope walls with development. The failures in the orebody were known to be structurally controlled where large scale structures were present in the stope backs. The stability graph does not appear to adequately account for structural effects.

The ELOS values were investigated further to determine the controlling factors for overbreak due to the rock mass conditions, as opposed to structural controls. The ELOS values were compared with HR and stope wall angle. The stope walls include hangingwall, footwall, and side walls. The backs were not included, and as a result, effectively exclude the structurally controlled failures. The results are shown in Figures 10 and 11. 


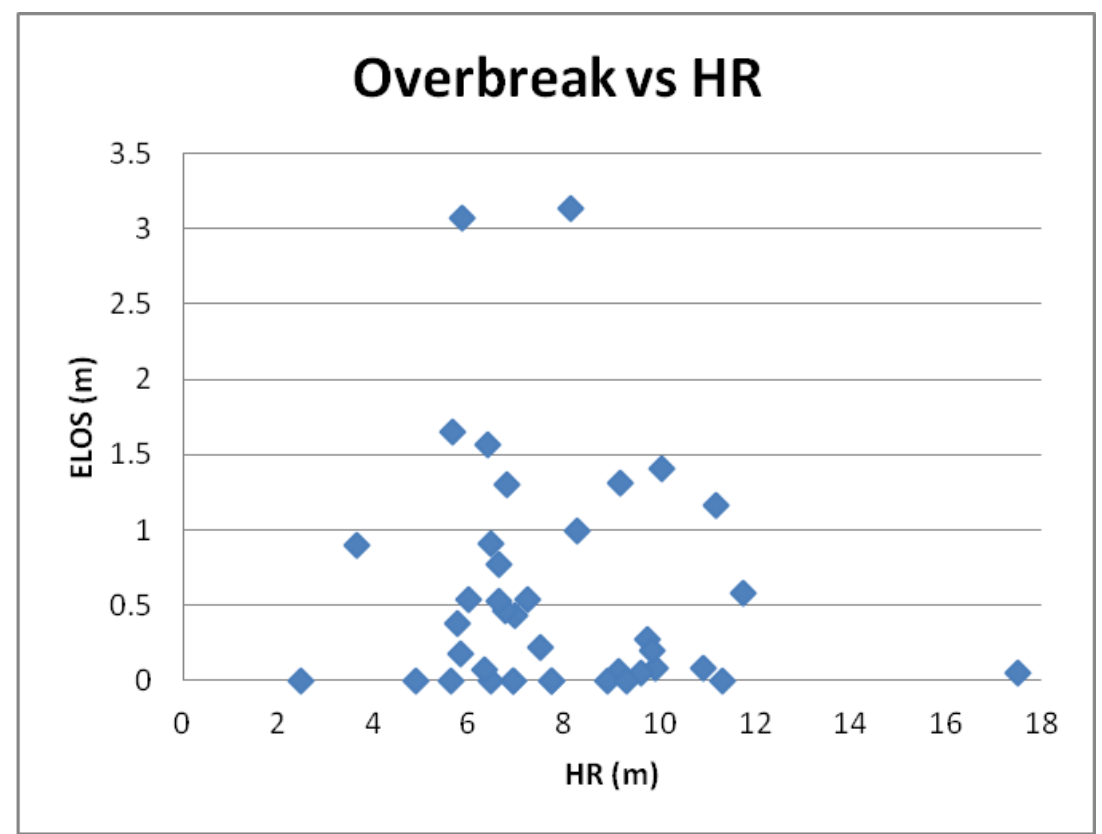

Figure 10 Plot showing the relationship of overbreak (ELOS) and HR

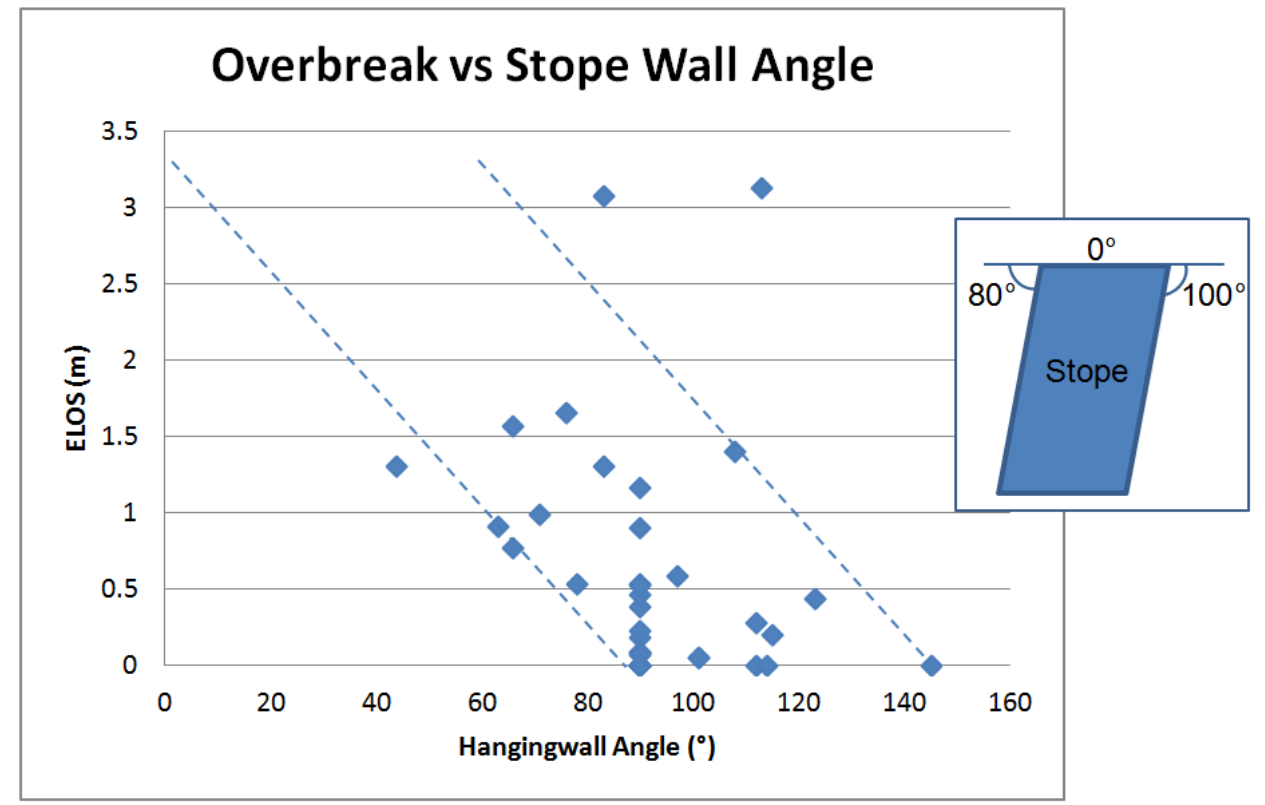

Figure 11 Plot showing the relationship of overbreak (ELOS) and stope wall angle

No clear relationship was found between ELOS and HR. The relationship between ELOS and stope wall angle suggests that overbreak reduces with higher stope wall angles. This result leads to the possibility that overbreak might be largely controlled by gravitational wedge failures.

\section{$5 \quad$ Design changes}

\subsection{Ground support}

Following investigation into the causes of the back failures in the No. 1 and No. 3 stopes, the cable bolt designs for subsequent stope backs were changed. This included an allowance for additional development in the backs for the primary purpose of installing ground support and reinforcement. Most of the stope backs were reinforced with $10 \mathrm{~m}$ cable bolts on a ring spacing of $2.5 \mathrm{~m}$. 
The failures that occurred in these more heavily-reinforced stope backs were significantly smaller than the combined No. 1 and No. 3 failure (5-11\% of the failed volume). To further reduce these failures the back reinforcement design was later changed to decrease the cable bolt length to $8 \mathrm{~m}$ and decrease the ring spacing to $2 \mathrm{~m}$. This design was successful in the last extracted stope (No. 11). The estimated cost increase of installing additional development and cable bolts to implement these changes to stope back reinforcement is in the order of $45 \%$.

Stope hangingwalls were reinforced with $10 \mathrm{~m}$ cable bolts on a ring spacing of $2.5 \mathrm{~m}$. The sublevel spacing of $25 \mathrm{~m}$ formed unsupported spans with an average HR of $6.7 \mathrm{~m}$. No failures occurred from hangingwalls and the overbreak was considered to be acceptable. The acceptability criteria were not related to ELOS but to the occurrence of failure. The unsupported span was increased to a HR of $9.2 \mathrm{~m}$ for the No. 9 stope.

Brow cable bolts were not initially installed as a standard. A significant failure occurred in one brow in the No. 1 stope, where the collars of several production rings were lost and the area required rehab. As a result production was delayed by several months. Stope brows were then reinforced with a minimum of three $6 \mathrm{~m}$ cable bolts as a standard. One further brow failure occurred in the No. 9 stope due to a change in the firing plan. One of the firing shapes was extended which placed the brow within an intersection with an $8 \mathrm{~m}$ span. This resulted in a change to the communications process between the drill and blast engineers and the geotechnical engineers. Although the failures occurred during stope blasts, the potential exists for brow failures to occur during production activities. Installation of standard brow reinforcement decreases the risk of this occurring.

The standard intersection reinforcement pattern was changed for all development in and around the stopes after the mining experience from the central panel. The limited damage that was observed in development led to a change from $9 \mathrm{~m}$ cable bolts to a pattern with only $6 \mathrm{~m}$ cable bolts resulting in a saving in both cost and time.

The procedure for pastefilling was changed to ensure that stopes are tight-filled to prevent large spans forming in the stope backs. This change, together with dense ground reinforcement, was successful in helping to limit the size of back failures.

\section{$5.2 \quad$ Stopes}

Based on the success of stope extraction in the orebody in terms of stable hangingwalls, and the recognition that the initial designs were probably conservative, the strike length of the No. 9 stope was doubled. Although reinforcement designs in the hangingwall were not changed, the unsupported HR was increased from 6.5 to $9.2 \mathrm{~m}$. The overbreak that occurred from the hangingwall in the No. 9 stope was higher to that of previously extracted stopes but still acceptable because no failure occurred from this stope wall.

\section{Conclusions}

The rock mass of the orebody described in this review is of a high quality and large stopes have been successfully extracted using a primary/secondary sublevel long-hole open-stoping method.

Changes to ground reinforcement in stope backs were successfully implemented and led to a decrease in stope dilution of $90 \%$ by volume. The estimated cost increase of installing additional development and cable bolts to the stope backs is in the order of $45 \%$. Standard stope brow reinforcement was introduced leading to fewer delays in production and improved brow stability.

Stope designs became less conservative as stoping experience was gained. As a result the unsupported spans were increased in the hangingwall. Stability was nonetheless maintained at acceptable levels.

Changes to ground reinforcement and stope designs led to cost savings in terms of acceptable stope dilution, fewer time delays and production losses, and direct cost savings for reinforcement. 
The published stability graph methods met with limited success in their application to this orebody. Failures were structurally controlled and best managed with dense ground reinforcement and effective passive support by tight-filling adjacent stopes. Analysis of the stope hangingwall performance indicates that the amount of overbreak decreases as stope wall angles are increased, hence overbreak might be largely controlled by gravitational wedge failures. These conclusions highlight the importance of reviewing stope performance by applying an engineering approach, which extends beyond empirical methods.

\section{References}

Barton, N.R., Lien, R. and Lunde, J. (1974) Engineering classification of jointed rock masses for the design of tunnel support, Rock Mechanics, Vol. 6, pp. 189-236.

Calvert, T.M., Simpson, J.B. and Sandy, M.P. (2000) Open stope design at Normandy Golden Grove operations, in Proceedings Massmin 2000, G. Chitombo (ed), 29 October to 2 November 2000, Brisbane, Australia, Australian Institute of Mining and Metallurgy, Melbourne, pp. 653-659.

Deere, D.U. (1968) Geologic Considerations, Chapter 1 of Rock Mechanics in Engineering Practice, Wiley, New York, pp. 1-20.

Hoek, E. and Diederichs, M. (1989) Dips - A Program for plotting, analysis and presentation of structural geology data using spherical projection techniques, Rock Engineering Group, University of Toronto.

Hutchinson, D.J. and Diederichs, M. (1996) Cablebolting in Underground Mines, BiTech Publishers Ltd., Chapter 2.17.

Mathews, K.E., Hoek, E., Wyllie, D.C. and Steward, S.B.V. (1980) Prediction of Stable Excavation for Mining at Depths Below $1000 \mathrm{~m}$ in Hard Rock, CANMET, Report Serial No 0SQ80-00081, Dss 17SQ23440-0-9020, Dept of Energy Mines and Resources, Ottawa.

Nickson, S.D. (1992) Cable support guidelines for underground hard rock mine operations, M.A.Sc. Thesis, Department of Mining and Mineral Processing, University of British Columbia, pp. 223.

Pakalnis, R., Nickson, S., Lunder, P., Clark, L., Milne, D. and Mah, P. (1996) Empirical methods for the design of mine structures, 11th Colloquium on Ground Control, March, Mining Assoc. of Quebec.

Potvin, Y. (1988) Empirical open stope design in Canada, Ph.D. Thesis, Department of Mining and Mineral Processing, University of British Columbia, pp. 343. 